\title{
PECADOS Y VICIOS EN LA ANDALUCÍA MODERNA (SIGLOS XVI-XVIII). UN RETRATO MÓVIL DE LA VIDA COTIDIANA
}

\author{
MARÍA RUIZ ORTIZ \\ Jaén, Ediciones Rubeo, 2013, 384 páginas \\ ISBN: 978-84-94110-40-5
}

En estos tiempos que corren, de continuos recortes a las labores investigadoras, y de un fuerte descrédito social sobre las humanidades, dedicarse a una actividad intelectual tan noble como el de producir conocimiento sin ninguna virtualidad práctica, constituye toda una heroicidad desde el punto de vista intelectual, tanto más cuanto que todo ello no va a generar ninguna gratificación académica, habida cuenta del fuerte grado de cerrazón que padece una institución universitaria en la cual la capacidad de relevo generacional se ha reducido al mínimo, y en la que, en muchos casos, sobre el último superviviente va a recaer la ingrata tarea de clausurar el edificio. Dado este panorama, de suma oscuridad, pero es en el que nos ha tocado vivir, resulta de todo punto admirable seguir encontrando a personas que de una forma absolutamente desinteresada persistan en su dedicación a las encomiables y sanas tareas de saber y de conocer, aunque solamente sea por curiosidad intelectual o por una mera gratificación personal. Si a ello le añadimos un producto intelectualmente bien concebido, y formalmente bien presentado, la admiración es doble.

Y todo esto se puede aplicar al objeto de nuestro comentario, la obra de María Ruiz Ortiz sobre los numerosos pecados y vicios que, en opinión de sus celosos directores espirituales, afectaban a la Andalucía de la Modernidad. El libro, fruto de una tesis doctoral presentada recientemente en la universidad de Córdoba, aborda una cuestión fundamental para nuestro mejor conocimiento de la sociedad andaluza del Antiguo Régimen, a saber, el fuerte peso de la Iglesia en el control de las conductas y en el autoanálisis de las conciencias, derivado todo ello de la práctica de la confesión. Figura poco estudiada, el confesor juega un papel fundamental en la vida religiosa de la Modernidad. A él se le desvelan miedos, temores, pecados, vicios y desafueros, y de su mayor o menor nivel de comprensión se derivarán conciencias tranquilas, temerosas o escrupulosas. Es por ello que, en una sociedad en la que todos estos asuntos se seguían tomando bastante en serio, debates teológicos que a nosotros nos puedan resultar tan ajenos como los derivados de la 
difusión de las ideas probabilistas, resultaban de gran importancia. Una actitud comprensiva ante las pequeñas debilidades humanas (para las grandes, no había solución) podía atraer conciencias a los confesionarios, del mismo modo que una postura rígida podía espantarlas, y, de hecho, el éxito que obtuvieron los jesuitas en la modernidad como confesores y directores espirituales hay que relacionarlo con su talante condescendiente.

Pero no solamente había pecados comunes para todos los católicos, sino también pecados específicos en función de la situación socio-profesional y de la condición sexual de cada uno. Ello responde a una doble motivación: en primer lugar, la sociedad del Antiguo Régimen sigue siendo una sociedad donde el concepto de estados sigue jugando una gran importancia, y de la pertenencia al mismo se derivan toda una serie no sólo de privilegios sino también de obligaciones. En segundo término, esta misma doctrina acabó impregnando los planteamientos teológicos de la Iglesia católica. Frente a la absoluta rigidez de las iglesias protestantes, especialmente los calvinistas, para los cuales la salvación individual era algo que estaba escrito desde el mismo inicio de los tiempos, los católicos se caracterizaron por una actitud mucho más flexible, según la cual se podían salvar ricos y pobres, casados y célibes, clérigos y laicos, nobles y plebeyos, gobernantes y gobernados, siempre y cuando cumplieran con los deberes y obligaciones derivados de su condición. Naturalmente, todo ello había que reglamentarlo y codificarlo, y a esta tarea se dedicaron con encomiable celo los autores de los muchos manuales de confesores y tratados de teología moral que proliferaron por aquel entonces, en los cuales se proporcionaba una detallada relación no solamente de los pecados cometidos contra cada uno de los diez mandamientos, sino de los que podían seguirse del ejercicio de cualquier actividad profesional.

De todo esto y de mucho más trata el libro de María Ruiz Ortiz. En sucesivos capítulos nos habla del universo pecaminoso que podía afectar de modo particular a mundos tan diversos como los de maridos y mujeres, señores y siervos, artesanos y jugadores, mercaderes y buhoneros, comerciantes y prestamistas, médicos y boticarios, jueces y abogados, escribientes y alguaciles, maestros y alumnos, oficiales y soldados, o campesinos y pescadores. De su lectura no solamente se desprende la existencia de todo un mundo de probables transgresiones, sino también la de un complejo universo profesional, en el cual la dedicación a una actividad concreta contribuía a crear una identidad personal y una percepción del propio individuo por parte de la colectividad. Y todo ello se describe con oficio y maestría, con un estilo preocupado de divulgar y no del auto-lucimiento intelectual (lo que en demasiadas ocasiones sucede en nuestro oficio), pensando siempre en 
el lector, que es, en definitiva, en quien debe pensar siempre el historiador. Demasiadas veces olvidamos que somos productores de conocimiento, y que nuestra labor carece por completo de sentido si no somos capaces de interesar a la sociedad en nuestro afán por comprender mejor el pasado, no ya porque tenga alguna utilidad desde el punto de vista práctico, que no la tiene, a no ser que algún gobernante interesado pretenda encontrar conciencias identitarias; sino para satisfacer algo tan inherente a la condición humana como la curiosidad intelectual o el deseo de aprender, al menos para que nadie intente presentarnos mundos felices que nunca existieron, o sueños de prosperidad futura que sabemos nunca van a beneficiar a todos.

Esperamos y deseamos que la autora se siga dedicando a las tareas intelectuales e investigadoras, para las que está especialmente dotada. Desde nuestra modesta tribuna, le dedicamos todo nuestro reconocimiento académico y nuestra admiración personal, no solamente por un trabajo muy bien hecho, sino por su constancia y su dedicación al poco lucido pero muy lúcido empeño por conocer y comprender mejor un pasado que siempre, de un modo u otro, acaba dejando su huella.

Arturo Morgado García

Universidad de Cádiz 